\title{
LXXII. “Good seeing”
}

\section{S.P. Langley}

To cite this article: S.P. Langley (1903) LXXII. “Good seeing” , Philosophical Magazine Series 6, 5:30, 674-677, DOI: 10.1080/14786440309462973

To link to this article: http://dx.doi.org/10.1080/14786440309462973

$$
\text { 册Published online: } 15 \text { Apr } 2009 .
$$

Submit your article to this journal 전

LII Article views: 3

Q View related articles ¿ 
of the scale-length, with euse and certainty, although the scale is very short. Under these circumstances, to claim one per cent. accuracy in interpolating is well within the mark. I should like to take this opportunity of emphasizing the remark made some yeirs ago by Professor Threlfall, that it is better to attain sensitiveness in a galvanometer by having a big mirror and first-rate optical conditions, than to push the electromagnetic sensitiveness to an extreme.

The apparatus described in this and the foregoing paper is intended for temperature measurements in an attempt at determining the Joule-Thomson effect, and was purchased out of a grant made for that purpose by the Royal Society, and I am glad to express to them my thanks for the liberality which has enabled me to undertake the work.

$$
\text { LXXII. "Good Seeing." By S. P. LANGLEY*. }
$$

[Plate XVII.]

Astrophysical Observatory, Washington, November 12, 1902 .

HVERY one who has used a telescope knows that our C) atmosphere is forever in pulsating motion, and troubling our vision of the heavenly bodies, during the most cloudless day or night, so that observatories are put even on high mountains to get rid of the disturbances in this atmosphere, which tend to make the image of every ohject tremulous and indefinite, and to prevent what the astronomer terms " good seeing."

I desire to speak to the Association about a device which I have recently essayed, for diminishing this universally known and dreaded "boiling" of the telescopic image, a difficulty which has existed always and everywhere since telescopes have been in use, and which has seemed so insurmountable that I believe it has hardly ever been thought of as subject to correction.

Hitherto it has been the endeavour of astronomers, so far as I know, to secure a more tranquil image by keeping the air in the telescope-tube, through which the rays pass, as quiet as possible, and for this purpose the walls of the tube have been made non-conducting, and extreme pains have been faken not to set up currents in the tube. With these precautions the "seeing" is, perhaps, a little better, but very little,

* Communicated by the Author.-A paper read before the Washington Meeting of the American Association for the Advancement of Science, December 30, 1902. 
than if none were used at all, the main difficulty having been always found insurmountable.

I have been led for some years to consider the conditions under which this " boiling" presents itself. It is not necessarily due to a high temperature of the external air, for the most perfect definition 1 have ever seen of any terrestrial object was obtained by me long since in the Harvard College Observatory, at Cambridge, with its great equatorial telescope, when, on the hottest day that I ever.knew in a New England summer, I directed it with a high power on the distant "south mark," which I expected to find almost indistinguishable from the "boiling." I remember my extreme surprise when, under a magnifying power of $300, I$ found the image as still as the lines of an engraving. This was an extraordinary exception to ordinary experience, and led me to take an interest in the subject. I have since pursued an inquiry to which this circumstance first directed my attention, and I bave done so at all altitudes, at one time residing on Aetna for this purpose, noting that even on high mountains vision was so far from being always clear that it was sometimes even much worse than at sea-level.

I have since come to the important conclusion that while the ordinary "boiling" is due to all the air between us and the sun or star through which the rays pass, the greater portion of it is due to the air immediately near us, probably within a few hundred yards, or even feet, from the telescope, and this has led me to ask whether it was not possible that some way to act upon this air could be found. Its nonuniformity leads to deformations of the image too complex to analyse here, which are caused not only by lateral vibrations of the cone of rays, but by its elongation and contraction.

For this purpose 1 have within the last few months been making experiments at the Smithsonian Astrophysical Observatory, first with a horizontal tube having three successive walls with air-spaces between, which was intended to give the maximum security which freedom from changes of temperature could afford. This Observatory being principally concerned with rays best studied in an image formed by reflexion, has no large dioptric telescope, on which account these experiments have been made with a reflector. I have no reason to suppose, however, that they will not be equally successful with a dioptric telescope.

A large part of the "boiling" of the image is due to air without the tube, but a not unimportant part to the air within it and, in the preliminary experiments the air, kept still in the tube by treating it with the ordinary precautions, 
was found to have little effect on the ordinary "boiling " of" the image, which so seriously prejudices the definition. An image-forming mirror, fed by a coelostat, was placed at the end of this triple-walled tube, which was itself sheltered by a canvas tent and contained the stillest air of the most uniform temperature which could be obtained. The "boiling" was but little diminished merely by inclosing the beam by this tube, which was only what had been anticipated from the ordinary experience of all astronomers.

The device which I had determined to try was one of a paradoxical character, for it proposed to substitute for this still air which gave the usual troubled image, agitated air, which it was hoped would give a still image. For the purpose of this new experiment, the horizontal telescope, using a reflector of 40 feet focus fed by a coelostat through the above tube, was connected with a fan run by an electric motor, which was arranged to draw out the ail from the inner tube, at the same time that it forced air in at different points in its length, so as to thus violently disturb and churn the air along all the path of tho beam from the coelostat to the solar image.

This first experiment gratifyingly reduced the "boiling" and produced an incontestibly stiller image than when still air was used. As a further test, a series of artificial double stars was now provided, and the concave mirror, acting both as collimator and objective, brought the images to focus, where they were examined by an eyepiece. With the stillest air obtainable, the images were not sharp and only the coarsest doubles were resolvable. Then the blower was started and the definition immediately became sharp. Violently stirring the air in the tuhe, then, eliminates all, or nearly all, the "boiling" of the stellar image which arises within the tube itself when nsing ordinary still air. This experiment concerned the air within the horizontal tube only.

I have next taken up the solar image formed by the mirror in the above tube. This is clearly improved by the stirring, but, as a supplementary improvement, I have wished to try a tube something like a prolonged dew-cap, but which is arranged to be inclined toward the sun, so that the beam may pass down it before being reflected by a mirror into the horizontal tube to form the image. This inclined tube is to be connected with the blower like the horizontal one, and the air in both can be stirred together, but experiment has not yet gone far enough to demonstrate whether it has, as is hoped, any superiority commensurate with the special mechanical difficulties involved in the research. Again, there 
was very marked "boiling" before starting the blower, which largely diminished while the blower was going.

I am not prepared to give quantitative estimates, which I hope to furnish later; but all observers to whom I have shown these early results have agreed, that if the "boiling" was not wholly cured, what remained was but a small fraction of that obtained with still air. I have not completed these experiments, which I am still pursuing at the Observatory, but they seem to me to give promise of an improvement of universa] interest to observers, which justifies the making of this early announcement. I had hoped to have shown the Association some photographs of the sun taken, first in the ordinary way, and again with the churned air, but the condition both of the sun and of the sky of late has prevented my obtaining them. I can, to my regret, only give here a photograph (Pl. XVII.) of the images of the artificial double stars as seen through ordinary conditions, as distinguished from those here mentioned, of artificial "good seeing."

LXXIII. On the Proportion of Argon in the Vapour rising from Liquid Air. By Lord RAYLEIGH, O.M., F.R.S.**

THE boiling-point of argon being intermediate between those of nitrogen and oxygen, it may be expected that any operations of evaporation and condensation which increase the oxygen relatively to the nitrogen will at the same time increase the argon relatively to the nitrogen and diminish it relatively to the oxygen. In the experiments about to be detailed the gas analysed was that given off from liquid air, either treshly collected, or after standing (with evaporation) for some time-from a day to a week. The analyses were for oxygen and for argon, and were made upon different, though similar, samples. Thus after an analysis of a sample for oxygen by Hempel's method with copper and ammonia, 4 or 5 litres would be collected in a graduated holder, and then the first analysis confirmed on a third sample. In no case, except one to be specified later, was the quantity of gas withdrawn sufficient to disturb sensibly the composition. The liquid was held in Dewar's vessels, but the evolution of gas from below was always sufficient to keep the mass well mixed.

The examination for argon was made in a large test-tube inverted over alkali, into which the gas was fed intermittently from the holder. The nitrogen was gradually oxidized by the electric discharge from a Ruhmkorff coil in connexion with the public supply of alternating current, the * Communicated by the Author.

Phil. Mag. S. 6. Vol. 5. No. 30. June 1903. 
Phil. Mag. Ser. 6, Vol. 5, Pl. XVII.

1.

The object,-a series of artificial stars.
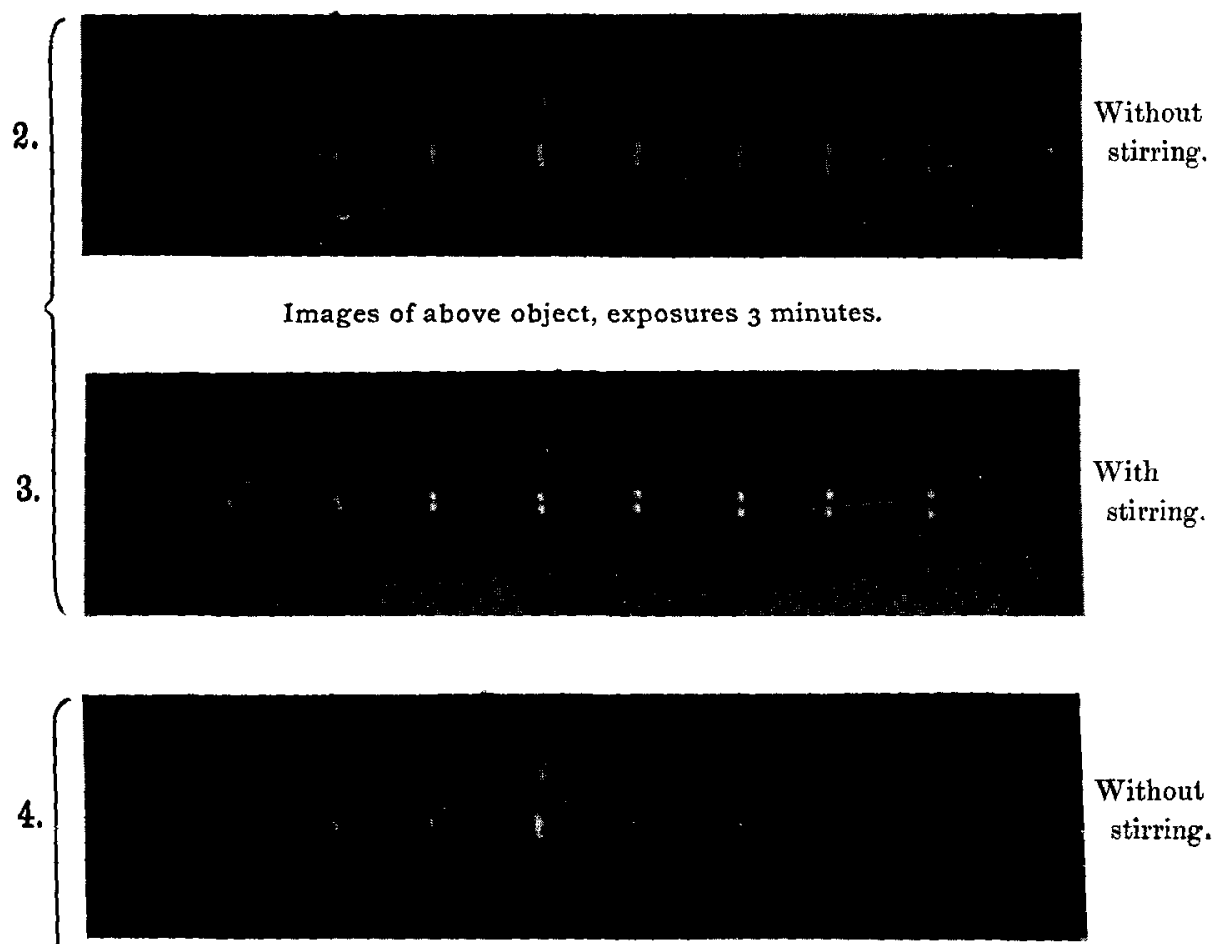

Images of above object, exposures 4 minutes.

Photographs illustrating Artificial Good Seeing, Astrophysical Observatory, Smithsonian Institution.

With

stirring.

5.

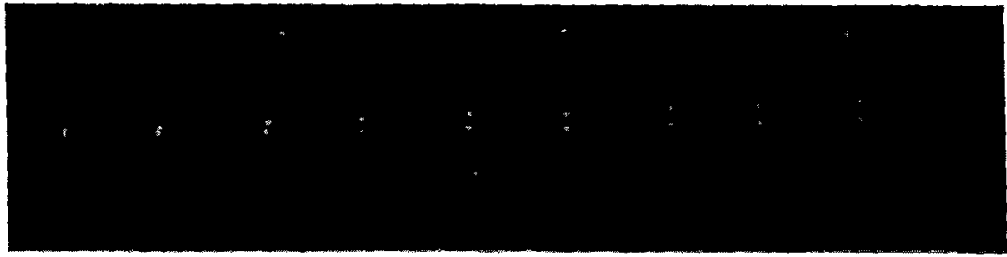

\section{Images of above object, exposures 4 minutes.}

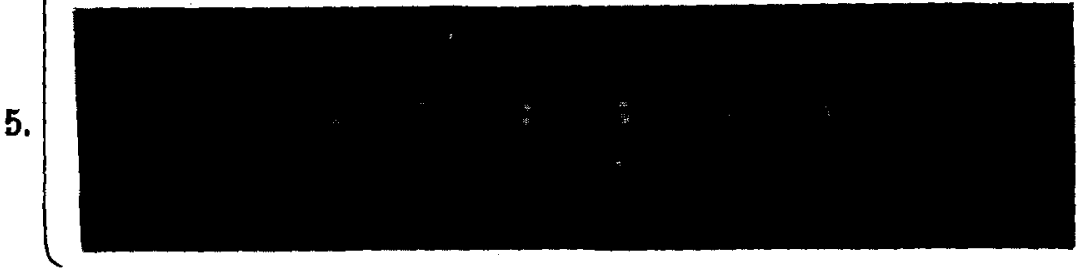

(a) 